\title{
Caracterização biométrica de frutos e sementes de mirindiba (Buchenavia tomentosa Eichler) e de inajá (Attalea maripa [Aubl.] Mart.) na região sul do Piauí, Brasil
}

\author{
Biometric characterization of fruits and seeds mirindiba (Buchenavia tomentosa \\ Eichler) and inajá (Attalea maripa [Aubl.] Mart.) in southern Piauí, Brazil
}

\author{
Alan Mario Zuffo1*, Gabriel de S. Gesteira², Joacir M. Zuffo Júnior³, Fabrício R. Andrade4, Igor \\ 0. Soares ${ }^{1}$, Everton V. Zambiazzi ${ }^{1}$, Scheila R. Guilherme ${ }^{2}$ e Adaniel S. dos Santos ${ }^{5}$
}

\author{
1 Universidade Federal de Lavras, Dpto. de Agricultura, Campus Universitário, CEP: 37200-000, Lavras, MG, Brasil; \\ 2 Universidade Federal de Lavras, Dpto. de Biologia, Campus Universitário, CEP: 37200-000, Lavras, MG, Brasil; \\ 3 Universidade do Estado de Mato Grosso, Dpto. de Agronomia, Campus de Nova Xavantina, BR-158, Km 148, CEP: 78690-000, Nova Xavantina, MT, Brasil; \\ 4 Instituto Federal de Mato Grosso, Dpto. de Agronomia, Campus Juína, CEP: 78320000, Juína, MT, Brasil; \\ 5 Universidade Federal do Piauí, Dpto. de Agricultura, Campus Universitário, CEP: 64900-000, Bom Jesus, PI, Brasil. \\ (*E-mail: alan_zuffo@hotmail.com) \\ http://dx.doi.org/10.19084/RCA15152
}

Recebido/received: 2015.11 .08

Aceite/accepted: 2016.01.13

\section{R E S U M O}

As espécies arbóreas tem potencial para aproveitamento em diversos setores e cadeias produtivas. Neste contexto, a biometria constitui-se em uma importante ferramenta para identificar as principais características intrínsecas ao fruto e a semente. Portanto, objetivou-se com este estudo caracterizar biometricamente os frutos e sementes de mirindiba e inajá e, correlacionar com os parâmetros dos frutos e sementes de cada espécie, a fim de obter informações sobre a variação das características biométricas. Analisaram-se 100 frutos frescos e 100 sementes, provenientes de 10 árvores de cada espécie, da região do sul do Piauí, quanto ao diâmetro equatorial, comprimento longitudinal, massa fresca, massa fresca da polpa do fruto e da semente, volume do fruto, índice de volume das sementes, umidade da polpa e umidade da semente. As características biométricas foram analisadas mediante distribuição de frequência, calculando-se o coeficiente de correlação de Spearman (rS) e o nível de significância através do teste t. Os frutos e sementes de mirindiba e inajá apresentam variabilidade para a maioria das características biométricas avaliadas, bem como correlação positiva predominante entre elas. Os frutos apresentam grande potencial econômico pelo alto rendimento de polpa observado, sendo possível a seleção de frutos com maior teor de polpa por características como o peso e tamanho do fruto.

Palavras-chave: biometria, Cerrado, correlação Spearman, espécies arbóreas.

\begin{abstract}
A B S T R A C T
Tree species have potential for use in various industries and supply chains. In this context, biometrics constitutes an important tool to identify key features intrinsic to the fruit and seed. Therefore, the aim of this study was to characterize biometrically the fruits and seeds of mirindiba and inajá and to correlate the fruit and seed parameters of each species in order to obtain information on biometric variation. Equatorial diameter, longitudinal length, fresh pulp, fresh weight of the fruit pulp and seed, fruit volume, volume index of seeds, humidity of the pulp and seed moisture collected in south of Piaui, were analyzed, considering 100 fresh fruits and 100 seeds from ten trees of each species. Biometric features were analyzed by frequency distribution, calculating the Spearman correlation coefficient (rs) and the level of significance using the test. The fruits and seeds of mirindiba and inajá exhibit variability for most biometric characteristics evaluated, as well as predominantly positive correlation between them. The fruits have great economic potential for the high yield of pulp observed, with the possible selection of fruits with higher pulp content by characteristics such as weight and fruit size.
\end{abstract}

Keywords: biometrics, Cerrado, Spearman correlation, tree species. 


\section{INTRODUÇÃO}

O Brasil apresenta grande diversidade de espécies arbóreas com potencial para aproveitamento em diversos setores e cadeias produtivas, como a produção de biodiesel, celulose, extração de substâncias farmacêuticas e nutracêuticas (Zani et al.,2013). Entre estas espécies, destaca-se a mirindiba (Buchenavia tomentosa Eichler, Combretaceae) e o inajá (Attalea maripa [Aubl.] Mart., Palmae).

A mirindiba é uma árvore de grande porte, com copa ampla e densa, e apresenta distribuição nos estados do Tocantins, Goiás, Bahia, Minas Gerais, Mato Grosso, Mato Grosso do Sul (Lorenzi, 2002) e Piauí. Sua madeira é utilizada na construção civil e produção de lenha e carvão, apresentando também grande potencial apícola e é indicada para recuperação de áreas degradadas (Azevedo et al., 2014).

O inajá é uma palmeira dossel com estipe único, podendo atingir os $20 \mathrm{~m}$ de altura e $100 \mathrm{~cm}$ de diâmetro a altura do peito (Ribeiro et al., 1999). A espécie está distribuída no norte da América do Sul em regiões de Floresta Tropical Úmida (Kahn, 1992) e, apresenta diversas finalidades como construção de coberturas de casas, alimentação humana e extração de óleo (Henderson et al., 1995; Lorenzi et al., 1996). Por apresentar alto teor de óleo em suas amêndoas (aproximadamente 60\%), o inajá possui grande potencial para produção de biodiesel (Corrêa et al., 2005; Costa e Marchi, 2008), propriedades nutracêuticas e farmacêuticas (Bezerra, 2011), ampliando a gama de possibilidades de extração de subprodutos.

Apesar destas espécies gerarem produtos com diversas finalidades e grande potencial econômico, sua exploração é limitada ao extrativismo da população local. Sendo assim, torna-se necessária a avaliação do estabelecimento e do desempenho destas espécies em áreas produtivas, bem como o estudo das características que envolvem os frutos, sementes e suas inter-relações.

Neste contexto, a biometria constitui-se em uma importante ferramenta para identificar as principais características intrínsecas ao fruto e à semente, as quais fornecerão subsídios para o melhor entendimento da dinâmica produtiva e exploração das espécies (Gusmão et al., 2006). São escassos os trabalhos de biometria envolvendo frutos e sementes de espécies arbóreas tropicais (Cruz et al., 2001; Cruz e Carvalho, 2003; Gusmão et al., 2006).

Para as espécies mirindiba e inajá existem relatos na literatura envolvendo apenas a morfologia dos frutos e sementes, sendo escassos os estudos envolvendo a biometria destas estruturas e suas correlações. Desta forma, este trabalho tem como objetivo determinar as características biométricas dos frutos e sementes de mirindiba e inajá, bem como correlacionar estas características.

\section{MATERIAL E MÉTODOS}

Os frutos foram coletados em uma área do Bioma Cerrado, cuja vegetação é de ocorrência natural, com aproximadamente $30 \mathrm{ha}$, equidistante cerca

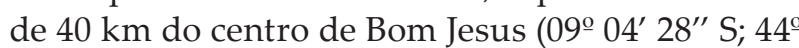
$\left.21^{\prime} 31^{\prime \prime} \mathrm{W}\right)$, com altitude média de $770 \mathrm{~m}$, cidade localizada no Sul do estado do Piauí, Brasil. O clima da região é do tipo Aw segundo a classificação de Köppen, com duas estações bem definidas, sendo uma seca que vai de maio a setembro e outra chuvosa que vai de outubro a abril. A temperatura média é de $26,5^{\circ} \mathrm{C}$ embora durante o ano seja comum atingir os $40^{\circ} \mathrm{C}$ e a precipitação é de 900 a $1200 \mathrm{~mm} \mathrm{ano}^{-1}$ (Viana, 2002).

$\mathrm{Na}$ área há presença de várias espécies florestais nativas do Cerrado. Dentre as diversas árvores surgem a mirindiba e o inajá, que não vêm sendo explorados, servindo apenas como alimentação dos animais silvestres. Ainda não existem trabalhos de florística e estrutura da comunidade arbórea e da dinâmica populacional dessas espécies para a região.

Os frutos maduros foram coletados quando caídos no solo, na área de projeção da copa de 10 árvores de cada espécie em estudo, durante a terceira semana do mês de setembro do ano de 2012, época de seca na região. Foram escolhidas árvores aleatórias na área, equidistantes no mínimo de $200 \mathrm{~m}$ umas das outras.

Para as medições, os frutos coletados foram acondicionados em caixas para o seu transporte até o Laboratório de Fitotecnia da Universidade Federal do Piauí, Campus Cinobelina Elvas. Iniciaramse imediatamente as avaliações biométricas. No laboratório, 120 frutos foram avaliados, selecionando-se aqueles visualmente sadios, 
Quadro 1 - Caracterização morfométrica dos frutos e sementes de mirindiba e inajá. N=100 frutos e N=100 sementes

\begin{tabular}{|c|c|c|c|c|c|}
\hline Parâmetro & Média & Assimetria & Curtose & D. Padrão & CV $(\%)$ \\
\hline \multicolumn{6}{|c|}{ Mirindiba (Buchenavia tomentosa Eichler) } \\
\hline Diâmetro do Fruto (mm) & $28,37(0,20)$ & $-0,73$ & 1,50 & 2,05 & 7,25 \\
\hline Comp. do Fruto (mm) & $34,32(0,23)$ & $-0,53$ & 0,61 & 2,37 & 6,91 \\
\hline Volume do Fruto $\left(\mathrm{cm}^{3}\right)$ & $37,99(0,84)$ & $-0,18$ & 0,19 & 8,44 & 22,22 \\
\hline Massa do Fruto (g) & $17,35(0,33)$ & $-0,10$ & 0,59 & 3,31 & 19,07 \\
\hline Massa da Polpa (g) & $14,15(0,29)$ & 0,09 & 0,88 & 2,98 & 21,09 \\
\hline Massa da Semente (g) & $3,19(0,05)$ & $-0,38$ & 0,51 & 0,52 & 16,27 \\
\hline Diâmetro Semente (mm) & $26,34(0,29)$ & $-4,29$ & 25,93 & 2,90 & 11,01 \\
\hline Comp. da Semente (mm) & $15,46(0,36)$ & $-1,64$ & 1,20 & 3,69 & 23,89 \\
\hline Largura da Semente (mm) & $2,65(0,03)$ & $-0,59$ & 0,23 & 0,39 & 14,75 \\
\hline Massa Seca Semente (g) & $13,07(0,18)$ & 4,98 & 30,94 & 1,85 & 14,16 \\
\hline Índice de Volume $\left(\mathrm{cm}^{3}\right)$ & $5,93(0,10)$ & 0,79 & 4,44 & 1,04 & 17,56 \\
\hline Umidade Semente $(\%)$ & $16,36(0,56)$ & 0,22 & 0,76 & 5,62 & 34,35 \\
\hline \multicolumn{6}{|c|}{ Inajá (Attalea maripa (Aubl.) Mart.) } \\
\hline Diâmetro do Fruto (mm) & $25,79(0,22)$ & $-0,69$ & 0,05 & 2,28 & 8,87 \\
\hline Comp. do Fruto (mm) & $44,09(0,37)$ & $-0,55$ & 0,14 & 3,74 & 8,48 \\
\hline Volume do Fruto $\left(\mathrm{cm}^{3}\right)$ & $13,83(0,32)$ & 0,006 & $-0,46$ & 3,25 & 23,53 \\
\hline Massa do Fruto (g) & $15,84(0,32)$ & $-0,43$ & $-0,37$ & 3,28 & 20,76 \\
\hline Massa da Casca (g) & $2,91(0,05)$ & 0,21 & $-0,25$ & 0,54 & 18,68 \\
\hline Massa da Polpa (g) & $7,07(0,18)$ & $-0,61$ & 0,32 & 1,88 & 26,72 \\
\hline Massa da Semente (g) & $5,85(0,13)$ & $-0,19$ & $-0,40$ & 1,37 & 23,46 \\
\hline Diâmetro Semente (mm) & $16,04(0,18)$ & $-0,76$ & 0,71 & 1,81 & 11,30 \\
\hline Comp. da Semente (mm) & $36,38(0,34)$ & $-0,53$ & $-0,07$ & 3,44 & 9,48 \\
\hline Massa Seca da Casca (g) & $1,69(0,02)$ & 0,17 & $-0,40$ & 0,27 & 16,01 \\
\hline Massa Seca da Polpa (g) & $2,82(0,07)$ & $-0,63$ & $-0,15$ & 0,71 & 25,21 \\
\hline Massa Seca Semente (g) & $5,15(0,11)$ & $-0,23$ & $-0,39$ & 1,18 & 23,04 \\
\hline Volume da Semente $\left(\mathrm{cm}^{3}\right)$ & $4,69(0,12)$ & 0,33 & $-0,09$ & 1,19 & 25,48 \\
\hline Umidade Polpa (\%) & $59,32(0,55)$ & $-1,43$ & 8,69 & 5,58 & 9,42 \\
\hline Umidade Semente $(\%)$ & $11,99(0,19)$ & 0,01 & 0,97 & 1,96 & 16,38 \\
\hline
\end{tabular}

( ): Erro padrão da média; D. Padrão: Desvio Padrão; CV: coeficiente de variação 
inteiros e sem deformação. Em seguida, entre estes, tomou-se de forma aleatória uma amostra de 100 frutos e, posteriormente determinou-se para a mirindiba as seguintes características: diâmetro equatorial (DEF), comprimento longitudinal (CLF) dos frutos com auxílio de um paquímetro digital (Clarke-150 mm). Após mensurar o tamanho, determinou-se a massa fresca (MFF) do fruto, massa fresca da polpa (MFP) e em seguida determinou-se o volume do fruto (VF) a partir do volume de água deslocado após a imersão do fruto em proveta contendo um volume conhecido de água conforme metodologia descrita por Basso (1999).

A remoção das sementes foi realizada após a retirada manualmente da polpa, e assim, determinou-se o comprimento longitudinal (CLS), largura (LS), diâmetro equatorial (DES), massa fresca (MFS) e massa seca (MSS) de 100 sementes. O índice de volume das sementes (IVS) que é o produto da relação entre o comprimento, largura e diâmetro (CLS x DES x LS), foi realizado a partir dos dados obtidos anteriormente. Para a umidade relativa das sementes (US), utilizou-se o método da estufa a $105{ }^{\circ} \mathrm{C} \pm 3{ }^{\circ} \mathrm{C}$ por 24 horas (Brasil, 2009). Para a mensuração da massa fresca do fruto e das sementes foi utilizada balança analítica de precisão $(0,001 \mathrm{~g})$.

Para a espécieinajáutilizou-se a mesma metodologia anterior, determinou-se o diâmetro equatorial do fruto (DEF), comprimento longitudinal do fruto (CLF), volume do fruto (VF), massa fresca do fruto (MFF), massa fresca da casca (MFC), massa fresca da polpa (MFP), massa fresca da semente (MFS), diâmetro equatorial semente (DES), comprimento longitudinal semente (CLS), massa seca da casca (MSC), massa seca da polpa (MSP), massa seca da semente (MSS), volume da semente (VS), umidade da polpa (UP) e umidade da semente (US).

As características biométricas dos frutos e sementes foram analisadas mediante distribuição de frequência. Foi calculado o coeficiente de correlação não paramétrico de Spearman (rS) e o respectivo nível de significância (p) entre as variáveis através do teste $t$ (Zar, 1996). Todas as análises estatísticas foram realizadas utilizando o programa computacional BIOESTAT 5.0 (Ayres et al., 2007).

\section{RESULTADOS E DISCUSSÃO}

A análise descritiva dos parâmetros avaliados nos frutos e sementes de mirindiba e inajá estão apresentadas no Quadro 1. Os valores de assimetria e curtose se aproximaram de zero para a maioria dos parâmetrosindicandodistribuiçãoaproximadamente normal, com exceção dos parâmetros diâmetro do fruto, diâmetro da semente, comprimento da semente, massa seca da semente e índice de volume de sementes na espécie da mirindiba, bem como umidade de polpa em inajá. Também foi observada grande variação para todos os parâmetros em ambas as espécies. O coeficiente de variação $(\mathrm{CV})$ variou de 6,91 a $34,35 \%$ para a mirindiba e de 8,48 a $26,72 \%$ no inajá, sendo que a maioria dos parâmetros avaliados em ambas as espécies apresentou valores inferiores a $20 \%$, o que indica boa precisão experimental. Zuffo et al. (2014) ao avaliar as características biométricas do baru (Dipteryx alata Vog.), também observaram variações em suas características, corroborando com os resultados deste estudo.

Dentre as variáveis biométricas obtidas para os frutos de mirindiba, cerca de 36\% destes apresentaram massa fresca (MFF) situada entre 14,36 a 17,55 g (Figura 1a), sendo que em aproximadamente 66\% dos casos a polpa (MFP) foi responsável por peso compreendido entre 12,13 a 17,96 g (Figura 1e), o que representa um grande potencial para o rendimento de polpa. Para o diâmetro equatorial dos frutos (DEF), 73\% destes apresentaram valores entre 26,73 a 30,93 mm (Figura 1b), sendo esta a característica com menor variação observada entre frutos. Já para o comprimento longitudinal (CLF), 34\% dos frutos apresentaram valores situados entre 33,42 a 35,40 mm (Figura 1c). As médias obtidas para diâmetro e comprimento do fruto foram de $28,37 \mathrm{~mm}$ e 34,32 $\mathrm{mm}$, respectivamente, valores inferiores aos obtidos para as mesmas características para a espécie Combretum leprosum Mart. (Combretaceae), que foram de 20,69 $\mathrm{mm}$ e $25,71 \mathrm{~mm}$, respectivamente (Paulino et al., 2013). Em 30\% dos frutos avaliados foram obtidos valores de volume (VF) situados entre 33 a 40,66 $\mathrm{cm}^{3}$ (Figura 1d), com média de $37,99 \mathrm{~cm}^{3}$.

Para as variáveis obtidas nas sementes de mirindiba, cerca de $38 \%$ destas apresentaram massa fresca (MFS) compreendido entre 3,00 a 3,43 $\mathrm{g}$ (Figura 1f), sendo que em $34 \%$ dos casos a massa seca (MSS) variou de 2,76 a 3,08 g (Figura 1j), o que representa um baixo teor de umidade. No entanto, para esta última característica (US) cerca de $42 \%$ 
das sementes avaliadas apresentaram teores situados entre 13,57 a 18,51\% (Figura 11) e média geral de $16,36 \%$, superando os valores médios obtidos por Salomão et al. (2003) e Azevedo et al. (2014) que foram de 5,4\% e 6,02\%, respectivamente.

Para o diâmetro equatorial da semente (DES), 71\% destas apresentaram valores situados entre 12,33 a 14,00 mm (Figura 1g), sendo esta a característica com a menor variação observada entre as sementes. Já para o comprimento longitudinal (CLS), cerca de $58 \%$ das sementes concentraram na classe de 26,27 a 30,24 mm (Figura 1h) e, para a largura (LS), 43\% apresentaram valores entre 15,00 a 17,18 mm (Figura 1i). As médias obtidas para diâmetro e comprimento da semente foram de 26,34 e 15,46 $\mathrm{mm}$, respectivamente, valores muito discrepantes dos obtidos para a espécie Combretum leprosum Mart. (Combretaceae), que foram de 5,07 e 12,46 $\mathrm{mm}$ para as mesmas características (Paulino et al., 2013). Para o índice de volume das sementes (IVS), $54 \%$ das sementes apresentaram valores situados entre 5,51 a 6,77 $\mathrm{cm}^{3}$ (Figura $1 \mathrm{k}$ ).

Nas variáveis biométricas obtidas para os frutos de inajá (Figura 2), aproximadamente 29\% destes apresentaram massa fresca (MFF) compreendida entre 16,88 a 19,22 g (Figura 2a), cuja média foi de $15,84 \mathrm{~g}$, valor superior ao descrito por Carvalho et al. (2007) para a mesma espécie, que obtiveram média de 12,65 g para esta característica. Em 32\% dos frutos avaliados foram obtidos valores para a massa fresca da casca (MFC) situados entre 3,04 a 3,47 g (Figura 2e), com média geral de 2,91 g, valor inferior ao obtido por Carvalho et al. (2007) que foi de 3,56 g. Em média, 1,69 g corresponderam à massa seca da casca (MSC), sendo que $31 \%$ das sementes na classe de 1,77 a 1,98 g. Para a massa fresca da polpa (MFP), $36 \%$ dos frutos apresentaram valores entre 6,63 a 8,27 g (Figura 2f), sendo que 33\% apresentaram massa seca da polpa (MSP) situada entre 2,68 a 3,20 g (Figura 2k), resultando em uma média de 59,32\% de umidade para esta característica. $\mathrm{O}$ valor médio para a massa da polpa foi de 7,07 $\mathrm{g}$, valor muito superior ao obtido por Carvalho et al. (2007), que foi de $1,4 \mathrm{~g}$. Os valores obtidos para o volume dos frutos (VF) indicam que 32\% destes apresentaram valores compreendidos entre 10,66 a 13,00 $\mathrm{cm}^{3}$ (Figura 2d).

Aproximadamente $32 \%$ dos frutos apresentaram diâmetro equatorial (DEF) compreendido entre 26,56 a 28,29 mm (Figura 2b), sendo que 35\% apresentaram comprimento longitudinal (CLF) situado entre 43,09 a 46,15 mm (Figura 2c). A média obtida para o diâmetro do fruto $(25,79 \mathrm{~mm})$ diferiu do apresentado por Carvalho et al. (2007), cuja média foi de 22,68 mm. No entanto, o valor obtido no presente trabalho foi ao encontro do apresentado por Araújo et al. (2000), que obtiveram média de 25,9 $\mathrm{mm}$ para esta característica. Já para o comprimento do fruto, a média obtida $(44,09 \mathrm{~mm})$ diferiu do apresentado por Araújo et al. (2000), cujo valor foi de 52,3 mm, mas se aproximaram do apresentado por Carvalho et al. (2007), que obtiveram média de $45,31 \mathrm{~mm}$.

Para as variáveis relacionadas as sementes de inajá, cerca de $28 \%$ destas apresentaram valores para a massa fresca da semente (MFS) compreendidos entre 4,16 a 5,20 g (Figura 2g) e média geral de 5,85 $\mathrm{g}$, diferindo do apresentado por Araújo et al. (2000) e Carvalho et al. (2007), os quais obtiveram médias de 6,62 g e 6,30 g, respectivamente, para esta característica. Já para a massa seca da semente, a média geral 5,15 g. Para a massa seca das sementes (MSS) cerca de $28 \%$ das sementes ficaram na classe de 3,63 a 4,57 g (Figura 2l), sendo que a média geral foi $5,15 \mathrm{~g}$. Este valor esta próximo ao obtido de Araújo et al. (2000), que foi de 5,75 g neste parâmetro. Em relação a umidade da polpa (UP), cerca de $67 \%$ concentram-se na classe de 53,83 a 61,84\%, com média de 59,32\% (Figura 2n). Já para a umidade da semente (US), foram distribuídas em duas classes centrais que representam $72 \%$ das sementes amostradas, na classe de 9,43 a 11,43\%, com 39\% das sementes e, na classe de 11,43 a 13,4 $\%$, com $33 \%$ dos frutos (Figura $2 b$ ), com média de $11,99 \%$, valor próximo do encontrado na literatura para a espécie (Araújo et al., 2000). Para o volume da semente (VS), aproximadamente $41 \%$ destas apresentaram valores compreendidos entre 3 e 4 $\mathrm{cm}^{3}$ (Figura 2m).

Em 32\% das sementes avaliadas foram obtidos valores de diâmetro equatorial (DES) situados entre 14,84 a 16,22 mm (Figura 2h) e, para o comprimento longitudinal (CLS) cerca de 31\% apresentaram valores entre 37,42 a 40,22 mm (Figura 2i). Estas características apresentaram médias gerais de 16,04 e $36,38 \mathrm{~mm}$, respectivamente, aproximando-se dos valores obtidos por Araújo et al. (2000), que foram de 17,7 e $38,4 \mathrm{~mm}$ para as mesmas características.

Além do estudo das características intrínsecas aos frutos e sementes, também é necessário avaliar a associação entre estas características. A 

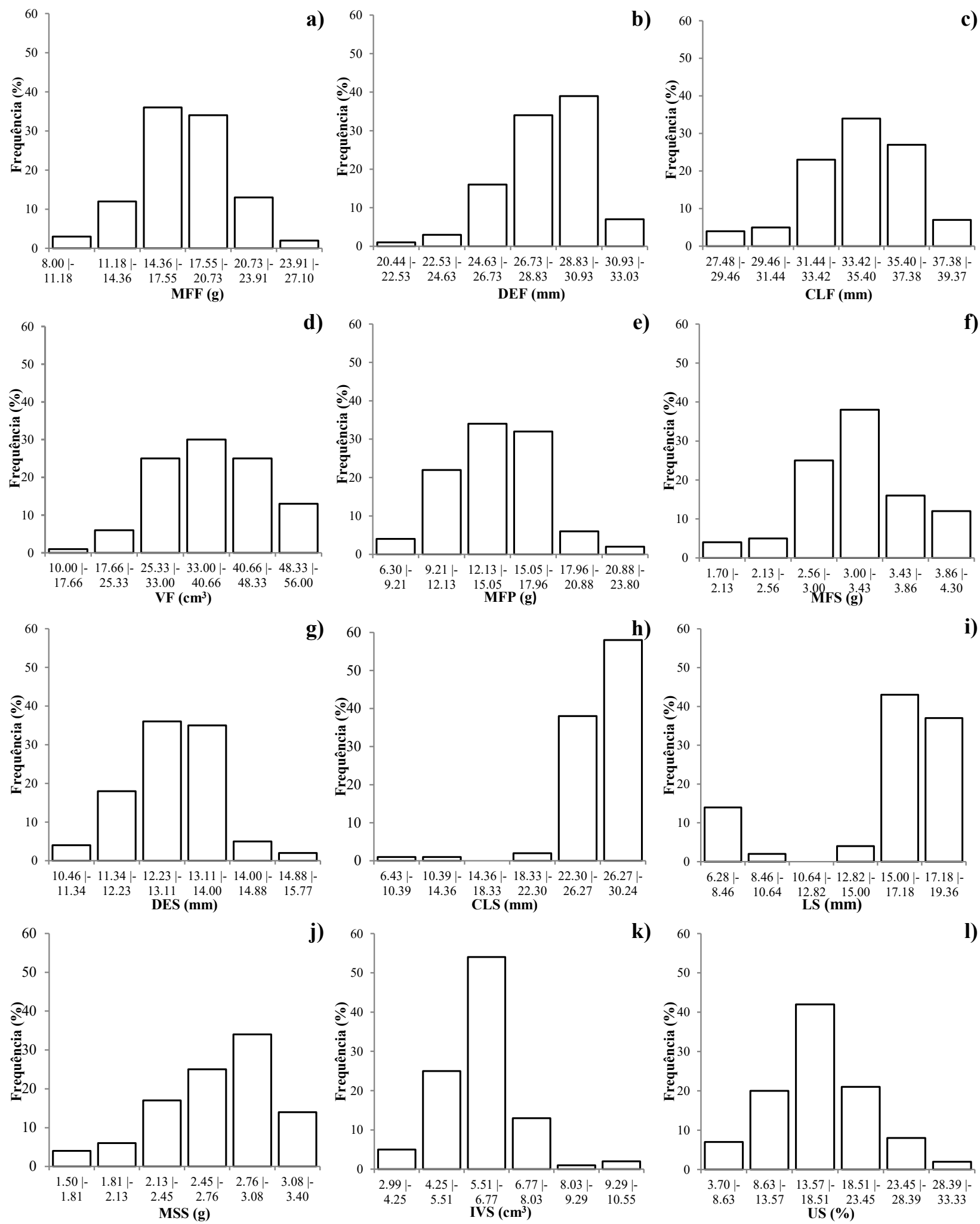

Figura 1 - Frequência da massa fresca (MFF, painel a), diâmetro equatorial (DEF, painel b), comprimento longitudinal (CLF, painel c), volume (VF, painel d) dos frutos de mirindiba, massa fresca da polpa (MFP, painel e). Massa fresca (MFS, painel f), diâmetro equatorial (DES, painel g), comprimento longitudinal (CLS, painel h), largura (LS, painel i), massa seca (MSS, painel j), índice de volume (IVS, painel k) e \% de umidade das sementes (US, painel l) de mirindiba no município de Bom Jesus, PI, no ano de 2012. $\mathrm{N}=100$ frutos e $\mathrm{N}=100$ sementes. 
associação entre características é importante pois permite verificar o grau de interferência de uma característica sobre outra de interesse econômico, bem como praticar a seleção indireta. Neste contexto, o coeficiente de correlação de Spearman (rS) é utilizado para expressar o grau de associação entre duas variáveis numéricas.

Os valores obtidos para a correlação de Spearman na mirindiba (Quadro 2) indicam que houve associação positiva e significativa entre todas as variáveis que envolvem o tamanho, massa e volume dos frutos. Os maiores valores observados foram entre a massa fresca do fruto (MFF) e massa fresca da polpa (MFP) $(0,990)$ e entre massa fresca do fruto (MFF) e o volume do fruto (VF) $(0,794)$. Este resultado era esperado devido à grande proporção da polpa na constituição do fruto e também da associação existente entre peso e volume para esta característica.

Quadro 2 - Correlação de Spearman (rS) para as variáveis biométricas dos frutos e sementes de mirindiba

\begin{tabular}{|c|c|c|c|c|c|c|c|c|c|c|c|}
\hline & MFF & DEF & CLF & VF & MFP & MFS & DES & CLS & LS & MSS & IVS \\
\hline DEF & $0,779 * *$ & 1 & & & & & & & & & \\
\hline CLF & $0,741 * *$ & $0,579 * *$ & 1 & & & & & & & & \\
\hline VF & $0,794 * *$ & $0,656^{* *}$ & $0,639 * *$ & 1 & & & & & & & \\
\hline MFP & $0,990 * *$ & $0,772 * *$ & $0,725 * *$ & $0,784 * *$ & 1 & & & & & & \\
\hline MFS & $0,662 * *$ & $0,553 * *$ & $0,610 * *$ & $0,538 * *$ & $0,570 * *$ & 1 & & & & & \\
\hline DES & $-0,004^{\mathrm{ns}}$ & $0,030^{\text {ns }}$ & $0,009^{\text {ns }}$ & $-0,046^{\mathrm{ns}}$ & $-0,021^{\mathrm{ns}}$ & $0,075^{\text {ns }}$ & 1 & & & & \\
\hline CLS & $0,066^{\text {ns }}$ & $0,022^{\text {ns }}$ & $-0,003^{\mathrm{ns}}$ & $0,087^{\mathrm{ns}}$ & $0,017^{\mathrm{ns}}$ & $0,256 * *$ & $0,134^{\mathrm{ns}}$ & 1 & & & \\
\hline LS & $-0,045^{\mathrm{ns}}$ & $-0,066^{\mathrm{ns}}$ & $0,085^{\mathrm{ns}}$ & $0,054^{\text {ns }}$ & $-0,069^{\text {ns }}$ & $0,119^{\text {ns }}$ & $0,100^{\text {ns }}$ & $0,437 * *$ & 1 & & \\
\hline MSS & $0,621 * *$ & $0,493 * *$ & $0,581 * *$ & $0,504 * *$ & $0,546^{* *}$ & $0,859 * *$ & $0,177^{\text {ns }}$ & $0,342 * *$ & $0,232^{*}$ & 1 & \\
\hline IVS & $0,029^{\text {ns }}$ & $0,020^{\text {ns }}$ & $-0,027^{\mathrm{ns}}$ & $0,012^{\text {ns }}$ & $-0,004^{\mathrm{ns}}$ & $0,173^{\mathrm{ns}}$ & $0,693 * *$ & $0,692 * *$ & $0,412 * *$ & $0,354 * *$ & 1 \\
\hline US & $0,256^{*}$ & $0,291 *$ & $0,182^{\text {ns }}$ & $0,230^{*}$ & $0,203^{*}$ & $0,444 * *$ & $-0,100^{\mathrm{ns}}$ & $-0,082^{\mathrm{ns}}$ & $-0,189^{\text {ns }}$ & $0,029^{\text {ns }}$ & $-0,273 * *$ \\
\hline
\end{tabular}

**significativo a $1 \%$ de probabilidade; *significativo a $5 \%$ de probabilidade; ns: não-significativo.

Quadro 3 - Correlação de Spearman (rS) para as variáveis biométricas dos frutos e sementes de inajá

\begin{tabular}{|c|c|c|c|c|c|c|c|c|c|c|c|c|c|c|}
\hline & MFF & $\mathrm{DEF}$ & CLF & VF & MFC & MFP & MFS & DES & CLS & MSC & MSP & MSS & VS & UP \\
\hline $\mathrm{DEF}$ & $0,800 * *$ & 1 & & & & & & & & & & & & \\
\hline CLF & $0,805^{* *}$ & $0,604 * *$ & 1 & & & & & & & & & & & \\
\hline VF & $0,832 * *$ & $0,744 * *$ & $0,681 * *$ & 1 & & & & & & & & & & \\
\hline MFC & $0,594^{* *}$ & $0,516^{* *}$ & $0,337 * *$ & $0,527^{* *}$ & 1 & & & & & & & & & \\
\hline MFP & $0,920 * *$ & $0,705 * *$ & $0,785 * *$ & $0,758 * *$ & $0,340 * *$ & 1 & & & & & & & & \\
\hline MFS & $0,911 * *$ & $0,790 * *$ & $0,744 * *$ & $0,784 * *$ & $0,600 * *$ & $0,728 * *$ & 1 & & & & & & & \\
\hline DES & $0,716^{* *}$ & $0,610 * *$ & $0,516^{* *}$ & $0,569 * *$ & $0,482 * *$ & $0,558 * *$ & $0,798 * *$ & 1 & & & & & & \\
\hline CLS & $0,791 * *$ & $0,620 * *$ & $0,825 * *$ & $0,683^{* *}$ & $0,441^{* *}$ & $0,671^{* *}$ & $0,820 * *$ & $0,587 * *$ & 1 & & & & & \\
\hline MSC & $0,729 * *$ & $0,600 * *$ & $0,507 * *$ & $0,653^{* *}$ & $0,732 * *$ & $0,548 * *$ & $0,759 * *$ & $0,578 * *$ & $0,575^{* *}$ & 1 & & & & \\
\hline MSP & $0,840 * *$ & $0,710 * *$ & $0,750 * *$ & $0,703 * *$ & $0,354 * *$ & $0,890 * *$ & $0,706 * *$ & $0,489 * *$ & $0,623 * *$ & $0,543 * *$ & 1 & & & \\
\hline MSS & $0,911 * *$ & $0,760 * *$ & $0,737 * *$ & $0,776^{* *}$ & $0,583 * *$ & $0,741 * *$ & $0,984 * *$ & $0,784 * *$ & $0,810^{* *}$ & $0,768 * *$ & $0,723 * *$ & 1 & & \\
\hline VS & $0,716^{* *}$ & $0,627 * *$ & $0,577 * *$ & $0,674 * *$ & $0,509 * *$ & $0,574 * *$ & $0,777 * *$ & $0,620 * *$ & $0,616^{* *}$ & $0,623 * *$ & $0,537 * *$ & $0,774 * *$ & 1 & \\
\hline UP & $0,246^{*}$ & $0,148^{\mathrm{ns}}$ & $0,145^{\mathrm{ns}}$ & $0,190^{\mathrm{ns}}$ & $0,036^{\mathrm{ns}}$ & $0,290 * *$ & $0,165^{\mathrm{ns}}$ & $0,241^{*}$ & $0,165^{\mathrm{ns}}$ & $0,114^{\mathrm{ns}}$ & $-0,075^{\mathrm{ns}}$ & $0,165^{\mathrm{ns}}$ & $0,162^{\mathrm{ns}}$ & 1 \\
\hline US & $0,012^{\text {ns }}$ & $0,075^{\mathrm{ns}}$ & $0,007^{\mathrm{ns}}$ & $0,002^{\mathrm{ns}}$ & $0,206^{*}$ & $-0,180^{\mathrm{ns}}$ & $0,169^{\text {ns }}$ & $0,147^{\mathrm{ns}}$ & $0,020^{\mathrm{ns}}$ & $0,059^{\text {ns }}$ & $-0,169^{\mathrm{ns}}$ & $0,067^{\mathrm{ns}}$ & $0,040^{\text {ns }}$ & $-0,065^{\mathrm{ns}}$ \\
\hline
\end{tabular}



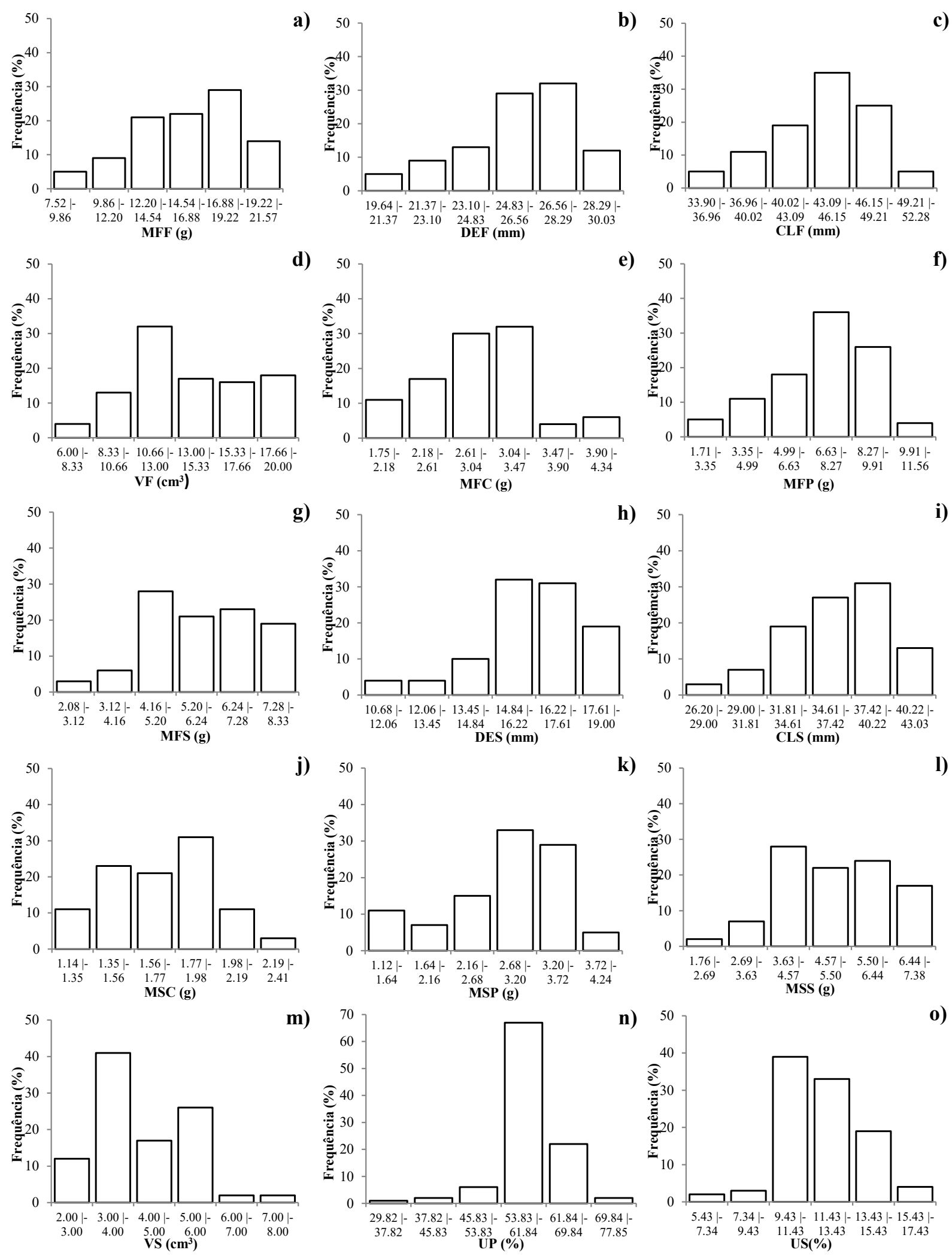

Figura 2 - Frequência da massa fresca (MFF, painel a), diâmetro equatorial (DEF, painel b), comprimento longitudinal (CLF, painel c), volume (VF, painel d) dos frutos de inajá, massa fresca da casca (MFC, painel e), massa fresca da polpa (MFP, painel f). Massa fresca (MFS, painel g), diâmetro equatorial (DES, painel h), comprimento longitudinal (CLS, painel i), massa seca da casca (MSC, painel j), massa seca (MSP, painel k), massa seca (MSS, painel l), volume da semente (VS, painel $\mathrm{m}$ ) e umidade da polpa (US, painel n) e umidade da polpa (US, painel o) de inajá no município de Bom Jesus, $\mathrm{PI}$, no ano de 2012. $\mathrm{N}=100$ frutos e $\mathrm{N}=100$ sementes. 
O diâmetro equatorial da semente (DES) apresentou correlação significativa e de alta magnitude apenas com o índice de volume da semente (IVS) $(0,693)$, provavelmente devido à sua contribuição na definição desta última variável. Com exceção do diâmetro equatorial (DES) e da umidade da semente (US), todas as outras variáveis apresentaram correlação positiva com a massa seca da semente (MSS), destacando sua forte associação com a massa fresca da semente (MFS) $(0,859)$. Esta última associação corrobora com a baixa variação observada para a umidade da semente (US). A largura da semente (LS) apresentou correlação positiva somente com o comprimento longitudinal da semente (CLS), massa seca (MSS) e índice de volume da semente (IVS). Houve associação significativa também entre o comprimento longitudinal da semente (CLS) e a massa fresca da semente (MFS).

Com exceção da umidade da semente (US), todas as variáveis inerentes à semente (DES, CLS, LS e MSS) apresentaram correlação significativa e positiva com o índice de volume da semente (IVS), resultado esperado devido a esta última variável ser obtida pelo produto entre o comprimento, largura e diâmetro da semente. A associação entre a umidade da semente (US) e o índice de volume da semente (IVS) foi negativa e significativa $(-0,273)$, indicando relação inversamente proporcional entre estas variáveis.

Os valores obtidos para a correlação de Spearman no inajá (Quadro 3) indicam que houve associação significativa e positiva entre as variáveis que envolvem o tamanho, massa e volume dos frutos, com exceção da umidade da polpa (UP), onde foi observada correlação apenas com a massa fresca do fruto (MFF) e a massa fresca da polpa (MFP). Esta associação era esperada devido à dependência do teor de água destas variáveis para a definição da umidade da polpa. Para as variáveis relacionadas à semente foram observados resultados semelhantes, com associação significativa e positiva entre todas as variáveis, com exceção apenas da umidade da semente (US).

As correlações observadas entre as variáveis do fruto e da semente, com exceção da umidade da polpa (UP) e da semente (US), foram todas significativas e positivas, indicando forte associação entre estas características. Os maiores valores foram observados entre a massa fresca (MFS) e a massa seca da semente (MSS) $(0,984)$, massa fresca MFP) e massa seca da polpa (MSP) $(0,890)$, e também da massa fresca do fruto (MFF) com a massa fresca da polpa (MFP) $(0,920)$, massa fresca da semente (MFS) $(0,911)$ e massa seca da semente (MSS) $(0,911)$. Estes valores confirmam a relação existente entre peso (MFF) e umidade (UF) dos componentes do fruto, bem como entre o peso fresco (MFF) e o teor de matéria seca (MSF) para seus componentes. A umidade da polpa (UP) apresentou correlação significativa apenas com o diâmetro da semente (DES) $(0,241)$, e a umidade da semente (US) se correlacionou positivamente apenas com a massa fresca da casca $(\mathrm{MFC})(0,206)$.

O conhecimento das variáveis biométricas e sua amplitude de variação é importante para a seleção, seja ela realizada no sentido de incrementar ou uniformizar estas características (Gonçalves et al., 2013). É importante ressaltar, que o conhecimento da correlação entre estas variáveis também auxilia no processo de seleção, pois permite definir a interferência da seleção realizada sobre uma característica em outra, bem como a realização de seleção indireta para características de difícil mensuração.

Por meio dos dados obtidos no presente trabalho, é possível inferir que a maioria das variáveis dos frutos e sementes avaliadas em mirindiba e inajá apresentaram alta correlação, sendo possível praticar seleção direta e indireta para estas características.

\section{CONCLUSÕES}

Os frutos e sementes de mirindiba e inajá apresentam variabilidade para a maioria das características biométricas avaliadas, bem como correlação positiva predominante entre elas. Os frutos apresentam grande potencial econômico pelo alto rendimento de polpa observado, sendo possível a seleção de frutos com maior teor de polpa por características como o peso e tamanho do fruto.

\section{AGRADECIMENTOS}

Os autores expressam seus agradecimentos ao CNPq (Conselho Nacional de Desenvolvimento Científico e Tecnológico) pela concessão de bolsas de Doutorado, a Universidade Federal do Piauí pelo apoio logístico. 


\section{REFERÊNCIAS BIBLIOGRÁFICAS}

Araújo, M.G.P; Leitão, A.M. e Mendonça, M.S. (2000) - Morfologia do fruto e da semente de inajá (Attalea maripa (Aubl.) Mart.) - PALMAE. Revista Brasileira de Sementes, vol. 22, n. 2, p. 31-38.

Azevedo, M.I.R.; Paiva, H.N. e Gomes, J.M. (2014) - Efeitos de substratos, luz e temperatura na germinação de sementes da espécie Buchenavia tomentosa Eichler (mirindiba) em condições de laboratório. Agri-Environmental Science, vol. 1, n. 1, p. 11-22.

Ayres, M.; Ayres Júnior, M. e Santos, A.A.S. (2007) - BioEstat 5.0: Aplicações estatísticas nas áreas das ciências biológicas e médicas. Belém, Sociedade Civil Mamirauá, 364 p.

Basso, S.M.S. (1999) - Caracterização morfológica e fixação biológica de nitrogênio de espécies de Adesmia DC. e Lotus L. 268 f. Tese de Doutoramento em Zootecnia, Universidade Federal do Rio Grande do Sul, Brasil, 268 p.

Bezerra, V.S. (2011) - O Inajá (Maximiliana maripa (Aubl.) Drude) como fonte alimentar e oleaginosa. Comunicado Técnico 129. Macapá, Embrapa.

Brasil (2009) - Regras para análise de sementes. Brasília, Mapa/ACS, 308 p.

Carvalho, A.L.; Ferreira, E.J.L.; Nascimento, J.F. e Regiani, A.M. (2007) - Aspectos da Biometria dos Cachos, Frutos e Sementes da Palmeira Najá (Maximiliana maripa (Aublet) Drude) na Região Leste do Estado do Acre. Revista Brasileira de Biociências, vol. 5, supl. 1, p. 228-230.

Corrêa, A.B.; Neto, D.C.F; Lima, D.K.B.; Costa, L.A.M; Chaar, J.S. e Flach, A. (2005) - Estudo do potencial oleaginoso de Maximiliana maripa (Correa) Drude como fonte de biodiesel. In: 28ํㅗ Reunião Anual da Sociedade Brasileira de Química. Poços de Caldas, SBQ.

Costa, C.J. e Marchi, E.C.S. (2008) - Germinação de sementes de palmeiras com potencial para produção de agroenergia. Informativo Abrates, vol. 18, n. 1, p. 39-50.

Cruz, E.D.; Carvalho, J.E.U. e Leão, N.V.M. (2001) - Métodos para superação da dormência e biometria de frutos e sementes de Parkia nitida Miquel. (LEGUMINOSAE MIMOSOIDEAE). Acta Amazônica, vol. 31, n. 2, p. $167-177$. http://dx.doi.org/10.1590/1809-43922001312177

Cruz, E.D. e Carvalho, J.E.U. (2003) - Biometria de frutos e sementes e germinação de curupixá (Micropholis cf. venulosa Mart. \& Eichler - Sapotaceae). Acta Amazônica, vol. 33, n. 3, p. 389-398. http://dx.doi.org/10.1590/S0044-59672003000300005

Gonçalves, L.G.V.; Andrade, F.R.; Marimon Junior, B.H.; Schossler, T.R.; Lenza, E. e Marimon, B.S. (2013) - Biometria de frutos e sementes de mangaba (Hancornia speciosa Gomes) em vegetação natural na região leste de Mato Grosso, Brasil. Revista de Ciências Agrárias, vol. 36, n. 1, p. 31-40.

Gusmão, E.; Vieira, F.A. e Fonseca Júnior, É.M. (2006) - Biometria de frutos e endocarpos de murici (Byrsonima verbascifolia Rich. ex A. Juss.). Cerne, vol. 12, n. 1, p. 84-91.

Henderson, A.; Galeano, G. e Bernal, R. (1995) - Field guide to the palms of the Americas. New York, Oxford University Press, 417 p.

Kahn, F. (1992) - Las palmeras de los bosques tropicales. Bulletin de L'Institute Français D'Études Andines, vol. 21, n. 2, p. $535-593$.

Lorenzi, H.; Souza, H.M.; Medeiros-Costa, J.T.; Cerqueira, L.S.C. e Behr, N. (1996) - Palmeiras no Brasil: nativas e exóticas. Nova Odessa, Plantarum, 303 p.

Lorenzi, H. (2002) - Árvores brasileiras: manual de identificação e cultivo de plantas arbóreas nativas do Brasil. $2^{2}$ ed. Nova Odessa, Editora Plantarum. 368 p.

Paulino, R.C.; Coelho, M.F.B.; Henriques, G.P.S.A.; Cordeiro, C.J.X. e Silva, A.C. (2013) - Características biométricas e descrição morfológica de frutos, sementes e plântulas de Combretum leprosum Mart. Revista Verde de Agroecologia e Desenvolvimento Sustentável, vol. 8, n. 5, p. 48-57.

Ribeiro, J.E.L.S.; Hopkins, M.J.G.; Vicentini, A.; Sothers, C.; Costa, M.A.; Martins, L.H.P.; Lohmann, L.G.; Assunção, P.A.C.L.; Pereira, E.; Silva, C.F.; Mesquita, M.R. e Procópio, L.C. (1999) - Flora da Reserva Ducke. Guia de identificação das plantas de uma floresta de terra-firme na Amazônia Central. Manaus, INPA, 816 p.

Salomão, A.N.; Sousa-Silva, J.C.; Davide, A.C.; Gonzáles, S.; Torres, R.A.A.; Wetzel, M.M.V.S.; Firetti, F. e Caldas, L.S. (2003) - Germinação de Sementes e Produção de Mudas de Plantas do Cerrado. Brasília, Rede de Sementes do Cerrado, 96. p.

Viana, T.V.A.; Vasconcelos, D.V.; Azevedo, B.M. e Souza, V.F. (2002) - Estudo da aptidão agroclimática do Estado do Piauí para o cultivo da aceroleira. Ciência Agronômica, vol. 33, n. 2, p. 5-12.

Zani, L.B.; Morozesk, M.; Bonomo, M.M.; Rocha, L.D. e Corte, V.B. (2013) - A utilização e o potencial das sementes florestais. Natureza On Line, vol. 11, n. 3, p. 118-124.

Zar, J.H. (1996) - Biostatistical analysis. 4. ed. New Jersey, River, Prentice-Hall/Upper Saddle. 662 p.

Zuffo, A.M.; Andrade, F.R. e Zuffo Júnior, J.M. (2014) - Caracterização biométrica de frutos e sementes de baru (Dipteryx alata Vog.) na região leste de Mato Grosso, Brasil. Revista de Ciências Agrárias, vol. 37, n. 4, p. 463-471. 